\title{
OPTIMIZACIÓN DE LA EFICIENCIA DE SISTEMAS FOTOVOLTAICOS A TRAVÉS DE RECOLECCIÓN SOLAR, BASADA EN LENTES DE FRESNEL
}

\section{Omar Ormachea y Daniel Serna}

\section{RESUMEN}

Se diseñó y construyó un prototipo funcional de un sistema fotovoltaico (SFV) con el objetivo principal de incrementar la eficiencia de sistemas fotovoltaicos convencionales. Este nuevo sistema implementa elementos de óptica y utiliza sistemas de selección de longitud de onda que permiten un uso efectivo del espectro electromagnético solar. Se obtuvo un incremento aproximado del $180 \%$ de la potencia promedio con el nuevo sistema, en comparación a los sistemas sin la modificación mencionada. Uno de los resultados más importante del método usado, es que la temperatura de las células fotovoltaicas, aún con la luz concentrada, no creció de manera significativa, en el mejor de los casos estudiados se registró un incremento de menos de $2{ }^{\circ} \mathrm{C}$, lo que muestra que los sistemas desarrollados son muy prometedores para una implementación real práctica en los SFV convencionales, como los utilizados en el área rural de Bolivia.

Palabras Clave: Células Fotovoltaicas, Energía Solar Concentrada, Lentes de Fresnel. 